\title{
Innovation Inc.
}

\section{NICK HERD}

INDEPENDENT SCHOLAR

\author{
Stuart Cunningham \\ Hidden Innovation: Policy, Industry and the Creative Sector \\ University of Queensland Press, Brisbane, 2013
}

ISBN 9780702249556

RRP $\$ 35.00$

In November 2013 the Commonwealth Department of Industry released its 2013 Australian Innovation System Report, the fourth in a series of such reports for the Australian Government. I begin this review of Hidden Innovation by referring to this report for two reasons. The first is to highlight the importance of the innovation system to economic policy makers. This is made clear from the outset of the report where it asserts: 'A high performing national innovation system is one that delivers productivity gains and social and environmental outcomes, leading to improved living standards.' (9) The second reason is to note that in a document nearly two hundred pages long, the discussion of the contribution of the creative industries to the national innovation system is minimal. Indeed the only contribution is made by Stuart Cunningham, the author of Hidden Innovation. The fact that creative industries are there at all is a testament to the tireless work of Cunningham, not only in advocacy, but also as an intellectual entrepreneur for the idea and the reality of 
creative industries. However, the relative absence of creative industries in this latest snapshot of the innovation system tells us something about how the discourse of innovation policy still does not enthusiastically embrace innovation in the creative industries. The traditional notion of innovation as located in the work of science, engineering and technology is still a dominant narrative.

In Hidden Innovation, Cunningham undertakes an impressive survey of the work that has been produced around the idea of innovation in the creative industries. The nub of the argument is that while innovation has been of great interest to economics (particularly the heterodox fields of evolutionary and innovation economics) and to economic policy makers, it is most often thought of in terms of scientific, technological or business process innovation. In addressing the absence of the cultural and creative industries from these understandings Cunningham seeks to do three things. The first is to identify examples of innovation in the creative industries that have been hidden from the larger discourse on innovation policy. The second is to argue that the creative industries 'are a key contributor to the innovation economies of developed economies', generating ideas, processes, products and talent that government innovation policies need to pay attention to. (1) The third is to promote within the new humanities-by which he means media, cultural and communication studies, and internet studies-'an interest in innovation as a way of refreshing the arguments and evidence for the role of our knowledge claims and research practices'. (208)

The book starts with an introduction that looks at the concept of innovation through the lens of disciplinary knowledges. The first chapter then steps back to examine the policy journey the concept of innovation has taken in the last few decades. Reference is made to C.P. Snow's famous speech on the 'two cultures' of the creative intellectual and the physical scientists, and the way innovation has been 'soldered onto' hard science and technology. There are then four chapters that each deal with a field of policy and practice-the creative enterprise, public service broadcasting, creative labour and creative cities-each filled with case studies that certainly make the point about the existence of innovation in creative industries. The final chapter is intended to be one of 'sustained realism' on the problematics of research into the creative sector innovation dynamic, such as that undertaken at the 
Australian Research Council Centre for Creative Industries and Innovation (CCI), which Cunningham leads.

The argument that innovation exists in the creative and cultural industries is relatively straightforward to make and should be more widely understood. Cunningham is clear on the basic understanding that when we talk about innovation it is not just about novelty, not just about the creation of new ideas, but about the 'application of those ideas for realised or potential economic, social or public benefit'. (4) This distinction is important because it can be a mistake to think that the advent of every new output of cultural production represents an innovation in aesthetic or industry practice. It is also a mistake to make comparisons between the creative artist and the research scientist since it misguidedly suggests that the individual is at the core of innovation and ignores the networked nature of innovation and the organisational dynamics of cultural production, which Cunningham fleshes out in his discussion of the creative enterprise. This network dynamic is especially the case with capitalist cultural production (film, television, music and so on) that exhibits both the relative autonomy of the creative labourer (artist) and the regularity of output that serves to underpin profitability in the circulation of cultural products.

That innovation may be 'hidden' can be attributed to both how innovation is defined and how it is measured, which, of course may be closely linked to each other. If one thinks of innovation in the terms associated with hard science and technology and measures by patents or expenditure on research and development (R\&D), then innovation in manufacturing processes or service delivery will go unnoticed. In 2007 the UK National Endowment for Science Technology and the Arts (NESTA) explored the concept of 'hidden innovation' by looking at innovation in so called 'low innovation' industries: oil production, retail banking, construction, legal aid services, education and the rehabilitation of offenders. A further study of hidden innovation in the creative industries in the United Kingdom demonstrated common examples of innovation in products services and in new business models.

Both these UK studies are referred to in Hidden Innovation as Cunningham explores case studies of innovation across the creative industries. Much of the innovation discussed is facilitated by the widespread availability of digital technology. For example, the old models of content distribution in the publishing, 
music and film industries are disrupted, first by piracy but more importantly by innovators such as Amazon, Apple and Netflix, who apply digital technology to the development of new business models for the distribution of content and, more recently, move back up the value chain into creating original content (for example, House of Cards by Netflix). In the chapter on public sector broadcasting Cunningham charts the way in which public service broadcasters, such as the BBC and $A B C$, are reinventing themselves through the innovation of multiplatform broadcasting to become the new 'public service media'. This innovation, however, is not without contestation from commercial media, such as News Corporation, which see it as the 'crowding out' of the competitive digital domain by publicly funded broadcasters.

If digital content is one area where the link between creative industries and innovation can be demonstrated, Cunningham also draws attention to design, 'thought of as a method or mindset that links research into new ideas on the one hand and the development of practical applications on the other', as the other sector that draws creative industries and innovation together. (179) Design is one of those occupational categories that is just as likely to be found embedded in industries outside the creative sector as inside it, as has been demonstrated by the work of the CCI on the 'creative trident', which describes the nature of employment in both the creative industries and other industries. Cunningham describes how design has come to be recognised as a crucial part of business innovation and productivity in the language of both business and industry policy.

There is no question that innovation exists in the creative industries: the ample case studies that Cunningham provides are a testament to that. Less easy to prove, however, are the grander claims made for the creative industries as an engine for growth in the wider economy. At the start of the book, Cunningham asserts:

My argument is that the creative industries are a key contributor to the innovation economies of developed countries. They contribute ideas, processes, products and, not least, talent, which can be repurposed within and outside the creative industries in ways that grow economies and drive productivity. (1)

This claim springs from earlier work by Cunningham and Potts on the four models of the creative industries and policy responses to those models developed since World War II. The first 'market failure' model provides the rationale for public support for 
the arts and screen production and is well accepted. The second model views sections of the creative industries, like broadcasting, as just another industry that can be managed through regulation. The third model sees creative industries as drivers of growth through novelty (that is, design solutions). The fourth model positions creative industries as an important part of the national innovation system and the 'knowledge base of the economy'. It is this fourth model that Cunningham wishes to see more widely accepted.

It is not that the idea of the creative industries has not been embraced. Situated at the intersection of policy, politics and industry, the turn to creative industries has emerged as a legitimising discourse that explicitly links ideas of creativity with those of economic and industrial development. This has mostly had a positive impact on the development of programs and policies in support of cultural production. In Australia we can trace this across the twenty years or so between the 'Creative Nation' cultural policy statement of 1994 and the 'Creative Australia' cultural policy of 2013. In the United Kingdom it can be seen in the Creative Industries Mapping Study of 1998, which came out of the Department of Media, Culture and Sport, and was largely instrumental in putting creative industries on the policy map in the United Kingdom and elsewhere. In the United States of America it can be seen in the embrace of Richard Florida's ideas about the creative class in policies for local and regional development. However, as important as this has been in defending public support for and investment in creative industries against the neoliberal critique of big government, I would argue there is some way to go before there is widespread acceptance of model four.

For this reason Hidden Innovation calls not only for the work on statistics to be continued but also for renewed research in the humanities on innovation and creative industries. In relation to statistics, recent work in the United Kingdom and Australia suggests there is reason to be hopeful. Ever since the Creative Industries Mapping Study stimulated interest in creative industries in the late nineties, the UK government has continued to measure their impact on the UK economy. In early 2014 the UK government released statistics that showed the gross value added (GVA) of the creative industries accounted for 5.2 per cent of the UK economy. This figure makes creative industries larger than mining or agriculture, but smaller than construction and financial services. However, the GVA for the creative industries has 
increased by 15 per cent since 2008, compared with 5.4 per cent for the UK economy as a whole, making it the sector of the UK economy least affected by the Global Financial Crisis. This is an important result because productivity growth is recognised as one of the indicators of an industry sector that is innovating. ${ }^{1}$

The Australian Bureau of Statistics has begun work on the development of satellite accounts for the creative industry that will provide a measure of the sectors' impact on the Australian economy. In February 2014, it released satellite accounts for 2008-09 that showed GVA for the cultural and creative industries estimated at $\$ 65.8$ billion. When Computer System Design and Related Services are included, as they are in the United Kingdom, then the GVA increases to $\$ 86$ billion. Compared to other sectors of the Australian economy, the cultural and creative industries are larger than agriculture, retail and education, but smaller than mining, manufacturing and financial services. No data is available about the growth of creative and cultural industries in Australia. ${ }^{2}$

Both sets of figures give further weight to the case for the economic significance of the creative industries and are likely to be welcomed by those outside the academy who work in these industries and those who are engaged in the policy and program delivery that support them. It is in the non-academic domain, where the discourse of economics and accounting dominates, that statistics help bolster the case for the impact and value of innovation in the creative industries.

Finally, I want to deal with Cunningham's call for a new version of interdisciplinarity that embraces innovation as an object of study. Cunningham quite rightly identifies that the powerful logic that equates innovation with science will not be displaced by curiosity-led research. That requires the kind of programmatic research that is currently being undertaken by the CCI and NESTA among others. The challenge, of course, is to make the case for why innovation, the study of innovation systems, and the place of creative industries in those systems, should be of interest to the new humanities in the first place. Unfortunately Hidden Innovation does not spend enough time making this case, particularly to those in the academy who might see the whole creative industries research project as a capitulation to neoliberal economics.

Like Cunningham, I would argue that there is a case to be made for a new interdisciplinary approach to innovation. I suggest we need to return to cultural 
studies' origins in questions of economics. I think we need to broaden what has to date been regarded as the political economy approach to cultural and communications studies by turning to the insights offered by economic sociology, field theory (not just that of Bourdieu) and institutional analysis (historical, rational choice and organisational institutionalism). These insights allow a move away from the unproductive synchronic structuration of the base/superstructure model of classical Marxism towards the diachronic structuration of fields or networks. My argument is that the creative industries can be considered as an institutional field constituted as a series of markets. In these markets there are relations of exchange between various agents. We need to understand better the structure of these markets and how they have been transformed.

This redefinition poses the question of what a proper political economy of culture and communications looks like when it is based in detailed analysis of fields of cultural production, such as those engaged by innovation studies. In the contemporary case, cultural production predominantly occurs within a network of social relations based on structured exchange that is understood as the capitalist market economy. As Hidden Innovation shows, innovation studies does not accept a one-dimensional account of capitalism or its markets but raises questions about networks and their structure, the role of entrepreneurs in networks, the impact of disruptive technology, the description of national innovation systems, the transfer of knowledge and so on. It is only through this engagement with the specificities of political economies, their individual agents and institutional mechanisms that media, cultural and communications studies can continue to evolve and adapt.

Hidden Innovation is an important book for the scope it covers and the breadth and depth of its survey of the thinking to date around creative industries and innovation. It also comprises a synthesis and revision of Cunningham's earlier work in this field. If it is not really for the general reader, its presentation and style nonetheless make it accessible. Readers who will get most from the book are those who already have some familiarity with the broad topic under discussion. It will find a ready audience among those who are engaged in the work of creative industries and innovation policy. It may not change the minds of those who are already sceptical about creative industries and innovation discourse, but I would challenge 
those who are interested in the field not to ignore the challenge Cunningham's book presents to the future of cultural and communications studies.

Nick Herd has a background in research, cultural policy and industry advocacy. He has held senior posts with the Australian Broadcasting Tribunal, Australian Broadcasting Authority, Screen Producers Association (as executive director), Screen Australia and the Australia Council. He is currently Manager, Research and Policy at Ausfilm. He is the author of Networking: Commercial Television in Australia (2012) and various other monographs and journal articles.

-NOTES

1 Department of Media, Culture and Sport, Creative Industries Economic Estimates,

<https://www.gov.uk/government/uploads/system/uploads/attachment_data/file/271008/Creative_ Industries_Economic_Estimates_-_January_2014.pdf>.

2 ABS, Australian National Accounts, Cultural and Creative Activity, Satellite Accounts, Experimental, <http://www.ausstats.abs.gov.au/ausstats/subscriber.nsf/0/EFFE2547EC51F5AACA257C78000C1B5 3/\$File/52710_2008-09.pdf>. 